\title{
Mathematical model for determination of the most advantageous conditions for formation of parts of aerospace engineering on the operations of the end milling
}

\author{
Dmitriy L. Skuratov ${ }^{1}$, Dmitriy V. Evdokimov ${ }^{1, *}$, and Dmitriy G. Fedorov ${ }^{1}$ \\ ${ }^{1}$ Korolev Samara National Research University, Samara, Russia
}

\begin{abstract}
A mathematical model has been introduced for determining the most advantageous conditions for parts formation when end milling operations. This model consists of a linear objective function and linear inequality constraints and takes into account the kinetics of thermal processes in the cutting zone. The equation determines the processing time was used as the objective function and constraint inequalities are related with the functional parameters and the parameters of the milling process and determines the quality of the machining.
\end{abstract}

\section{Introduction}

At the present time modern production has a steady trend which aimed at increasing of industrial products complexity and usage of the materials that cause certain difficulties in machining. This trend in many cases leads to necessity of producing high-precision parts with a complex shaped profile, working under conditions of alternating loads and high temperatures. Therefore, in the technological processes of manufacturing such parts, an important place is given to the operations of end milling. It should be noted that the maximum productivity of the process on these operations with stable provision of the specified requirements to the quality of machining can be ensured only with a scientifically justified choice of machining modes, which can be determined by mathematical model that allows to obtain rational machining modes for various variants of controlled parameters.

The mathematical model which has been presented in this paper for determining of the rational machining modes for final end milling includes a linear objective function and linear technical limitations-inequalities.

When designing of the technological process for parts manufacturing, the determining value for each operation is the correct choice of the tool life. The economic tool life or tool life which corresponding to greatest productivity is most often used in modern production conditions. Operation with maximum productivity is used in exceptional cases. In connection with the previously stated definition of a rational machining mode should be based exclusively on the economic life tool. Therefore, as an objective function for end milling, a machining time determining equation should be used.

\footnotetext{
${ }^{*}$ Corresponding author: dmitry.evd.ssau@gmail.com
} 


\section{Selection of objective function and technical limitations}

The equation of the objective function applied to the process of single-pass end milling:

$$
f_{m}=\frac{L}{S_{\mathrm{m}}}=\frac{L}{n_{m} S_{z} z},
$$

where $L$ - total length of the cutter travel relative to the workpiece, $\mathrm{mm} ; n_{m}$ - rotational speed of the mill, rpm; $S_{\mathrm{m}}$ - feed per minute, $\mathrm{mm} / \mathrm{min} ; S_{z}$ - feed per tooth, $\mathrm{mm} /$ tooth; $z$ - number of mill teeth.

The total length of the cutter travel relative to the workpiece is determined by $L=l_{m}+l_{1}+l_{2}$, where $l_{m}$ - distance passed by the mill in the feeding direction, $\mathrm{mm} ; l_{1}-$ the value corresponding to the penetration into the workpiece, $\mathrm{mm} ; l_{2}$ - value corresponding to the overrun of the mill, $\mathrm{mm}$.

The value of penetration into the workpiece during the end milling is defined as [1]:

$$
l_{1}=0,5 D_{m} \sin \psi,
$$

where $D_{m}-$ diameter of the end mill, mm; $\psi=\arccos \left(1-2 t_{m} / D_{m}\right) ; t_{m}-$ milling depth, mm.

\subsection{The limitation associated with the cutting properties of the tool (tool life)}

The cutting speed for milling, is calculated based on the condition of full using of the cutting properties of the tool, based on the inequality: $v \leq v_{m}$ (2).

where $v$-cutting speed, $\mathrm{m} / \mathrm{min} ; v_{m}$ - maximum permissible cutting speed for a given value of the tool life of the end $\mathrm{mill}, \mathrm{m} / \mathrm{min}$.

Using the values of $v$ and $v_{m}$, which are calculated from $v=\frac{\pi D_{m} n_{m}}{1000}$ and $\mathrm{v}_{m}=\frac{C_{\mathrm{v}} D_{m}^{q_{\mathrm{v}}}}{T^{m} S_{z}^{y_{\mathrm{v}}} t_{m}^{x_{\mathrm{v}}} B^{u_{\mathrm{v}}} p^{p_{\mathrm{v}}}}$ into inequality (2) and solving it relatively to $n_{m} S_{z} t_{m}$ the first technical limitation has been obtained:

$$
n_{m}\left(100 S_{z}\right)^{y_{\mathrm{v}}}\left(100 t_{m}\right)^{x_{\mathrm{v}}} \leq \frac{318 C_{\mathrm{v}} D_{m}^{\left(q_{\mathrm{v}}-1\right)} 100^{\left(x_{\mathrm{v}}+y_{\mathrm{v}}\right)}}{T^{m} B_{m}^{u_{\mathrm{v}}} z^{p_{\mathrm{v}}}},
$$

where $T$ - given tool life of the mill, min; $B_{m}$ - width of milling, $\mathrm{mm}$.

The values of the coefficient $C_{v}$ and indexes $m, x_{v}, y_{v}, q_{v}, u_{v}, p_{v}$ are given in the reference literature on machining modes, for example, in papers [1, 2]. In inequality (3) and subsequent technical constraints, for convenience of carrying out the calculations, it has been accepted instead of $S_{z} \rightarrow 100 S_{z}$ and instead of $t_{m} \rightarrow 100 t_{m}$, with the corresponding corrections in the right-hand side of the inequalities.

\subsection{Limitations related to capacity of the equipment}

The process of workpiece machining on metal cutting machines is possible to realize when 
the effective cutting power does not exceed the power which are supplied to the spindle of the machine that makes machining. Therefore, for end milling, as well as for the other types of machining, inequality [7] should be fulfilled:

$$
N_{\text {ef }} \leq 1,2 N_{\mathrm{sp}}
$$

where $N_{\text {ef }}$ is the effective power expended on the cutting process, $\mathrm{kW} ; N_{\mathrm{sp}}$ - power which are supplied to the spindle of the machine, $\mathrm{kW}$.

The second technical constraint becomes:

$$
n_{m}^{z_{N}}\left(100 S_{z}\right)^{y_{N}}\left(100 t_{m}\right)^{x_{N}} \leq \frac{1,2 N_{\mathrm{en}} \eta 100^{\left(x_{N}+y_{N}\right)}}{C_{N} 10^{-5} D_{m}^{q_{N}} B_{m} z k_{N 1} k_{N 2}},
$$

where $N_{\mathrm{en}}$ - power of the electric motor of the mechanism of the main movement of the machine or motor-spindle, $\mathrm{kW} ; \eta$ - efficiency of the kinematic chain of the main movement mechanism or motor-spindle. Values of $C_{N}$ coefficient and indexes $x_{N}, y_{N}$, $q_{N}, z_{N}$ for different machining conditions are given in [1, 2, 4].

Generalized constraint that takes into account the grade of machined and tool materials, the rigidity of the technological system, the roughness and the shape of the machined surfaces. When end milling process of different material groups, the feed per tooth should not exceed the value determined from the inequality:

$$
S_{z} \leq \frac{C_{S} D_{m}^{q}{ }^{q} k_{S 1} k_{S 2} k_{S 3} k_{S 4}}{t^{x_{S}} B_{m}^{u_{S}}}
$$

where $C_{S}$ - a constant coefficient for these cutting conditions, depending on the physical and mechanical properties and structure of the machined material and the material of the cutting part of the mill; $k_{S 1}$ - a coefficient that takes into account the rigidity of the technological system; $k_{S 2}$ - a coefficient that takes into account the grade of instrumental material; $k_{S 3}$ - coefficient that takes into account the roughness of the machined surface; $k_{S 4}-$ coefficient that takes into account the shape of the machined surface.

After solving (7) relative to $S_{z}, t_{m}$ the third technical constraint becomes:

$$
\left(100 S_{z}\right)\left(100 t_{m}\right)^{x_{S}} \leq \frac{C_{S} D_{m}^{q S}(100)^{\left(1+x_{S}\right)} k_{S 1} k_{S 2} k_{S 3} k_{S 4}}{B_{m}^{u S}} .
$$

The values of $C_{S}$ coefficient and indexes $x_{S}, q_{S}, u_{S}$ for various end milling conditions are presented in paper [1].

\subsection{The limitation arisen in connection with the average contact temperature of cutting during milling}

During machining, it is necessary to ensure conditions under which temperature in contact zone between mill and workpiece does not exceed the critical values. It is presented in:

$$
\theta \leq \theta_{\mathrm{cr}}
$$


where $\theta$ - average contact temperature in the cutting zone, ${ }^{\circ} \mathrm{C} ; \theta_{\mathrm{cr}}-$ critical temperature in the cutting zone, ${ }^{\circ} \mathrm{C}$.

The temperature in the cutting zone during end milling of workpieces can be determined by an empirical dependence:

$$
\theta=C_{\theta} \mathrm{v}^{z} S_{z}^{y_{\theta}} B_{m}{ }^{u_{\theta}}\left(\frac{t_{m}}{D_{m}}\right)^{x_{\theta}}
$$

where $C_{\theta}$ is the coefficient which determines the influence of machining conditions on the temperature in the cutting zone during end milling; $x_{\theta}, u_{\theta}, y_{\theta}, z_{\theta}$ - the indexes characterizing the magnitude of the $t_{m}, B_{m}, S_{z}$ and $v$ influence, respectively, on the magnitude of the cutting temperature [2].

If transfer the empirical relationship (10) and the formula for determining the cutting speed for milling into the inequality (9) and then solve it relative to $n_{m} S_{z} t_{m}$, the fourth technical constraint will have been obtained:

$$
n_{m}^{z_{\theta}}\left(100 S_{z}\right)^{y_{\theta}}\left(100 t_{m}\right)^{x_{\theta}} \leq \frac{318^{z_{\theta}} \cdot 100^{\left(x_{\theta}+y_{\theta}\right)} \theta_{\mathrm{cr}}}{C_{\theta} D_{m}^{\left(z_{\theta}-x_{\theta}\right)} B_{m}^{u_{\theta}}} .
$$

\subsection{Limitation related to the kinematic capabilities of equipment used for end milling}

When forming the workpiece, rotation frequency of the end mill, installed in the spindle or the motor-spindle of the machine and the minute feed of the machine table must be limited: fifth and sixth technical constraints:

$$
n_{m} \geq n_{s p \min }
$$

where $n_{\text {Ст min }}$ - minimum rotation frequency of the spindle (motor-spindle) of the machine, rpm;

$$
n_{m} \leq n_{s p \max }
$$

where $n_{s p \max }-$ maximum rotation frequency of the spindle of the machine, rpm;

- the seventh technical constraint: $S_{\mathrm{m}} \geq S_{\mathrm{m} . t \mathrm{~min}}$,

where $S_{\mathrm{m} . t \text { min }}$ - minimum minute feed of the machine table, $\mathrm{mm} / \mathrm{min}$. Considering that $S_{\mathrm{m}}=n_{m} S_{z} z$, in the final form, the seventh technical constraint can be presented in the following form:

$$
n_{m}\left(100 S_{z}\right) \geq \frac{100 S_{\mathrm{m} . t \min }}{z}
$$

- the eighth technical constraint $S_{\mathrm{m}} \leq S_{\mathrm{m} . t \text { max }}$;

$$
n_{m}\left(100 S_{z}\right) \leq \frac{100 S_{\mathrm{m} . t \max }}{z},
$$


where $S_{\mathrm{m} . t \max }-$ maximum minute feed of the machine table, $\mathrm{mm} / \mathrm{min}$.

\subsection{Limitations associated with the depth of cut during milling}

In the case of end milling, the cutting depth $t_{m}$ can not be less than a certain value for each tool and machined material $-t_{m \cdot \min }$. On the other hand, the cutting depth can not be greater than $t_{\text {m.max }}$, which is equal to the diameter of the end mill. Then the technical constraints related to the depth of cutting can be presented as:

- the ninth technical constraint: $100 t_{m} \geq 100 t_{\text {m.min }}$;

- the tenth technical constraint: $100 t_{m} \leq 100 t_{\text {m.max }}$.

\subsection{Limitations associated with the results of study of the thermal processes kinetics during cutting}

At the rate constant value of coolant supply to the cutting zone, the technical limitations allowing to take into account the kinetics of thermal processes in the machined zone are based on the use of diagrams linking the metastable material state diagrams with the cutting speed [8]:

$$
\begin{aligned}
& v \geq v_{\text {al.min }} \\
& \text { and } v \leq v_{\text {al.max }}
\end{aligned}
$$

where $v_{\text {al.max }}$ is the minimum allowed cutting speed, $\mathrm{m} / \mathrm{min} ; v_{\text {al.max }}$ - the maximum allowed cutting speed.

Solving inequalities (18) and (19) relatively to $n_{m}$, having previously presented $v$ in them how $v=\frac{\pi D_{m} n_{m}}{1000}$ to obtain the eleventh and twelfth technical constraints:

$$
\begin{aligned}
& n_{m} \geq \frac{1000 v_{\text {al.min }}}{\pi D_{m}} \\
& \text { and } n_{m} \leq \frac{1000 v_{\text {al.max }}}{\pi D_{m}}
\end{aligned}
$$

\section{Mathematical model}

The inequalities which were obtained earlier and connect the technical constraints with the elements of the cutting mode for milling, and the objective function were transformed to linear inequality constraints and a linear objective function: 


$$
\left\{\begin{array}{rr}
x_{1}+y_{v} x_{2}+ & x_{v} x_{3} \leq b_{1} \\
z_{N} x_{1}+y_{N} x_{2}+ & x_{N} x_{3} \leq b_{2} \\
x_{2}+ & x_{s} x_{3} \leq b_{3} \\
z_{\theta} x_{1}+y_{\theta} x_{2}+ & x_{\theta} x_{3} \leq b_{4} \\
x_{1} & \geq b_{5} \\
x_{1} & \leq b_{6} \\
x_{1}+x_{2} & \geq b_{7} \\
x_{1}+x_{2} & \leq b_{8} \\
& x_{3} \\
& \geq b_{9} \\
x_{3} & \leq b_{10} \\
& \geq b_{11} \\
x_{1} & \leq b_{12} \\
x_{1} &
\end{array}\right.
$$

where $x_{1}=\ln n_{m} ; x_{2}=\ln \left(100 S_{z}\right) ; x_{3}=\ln \left(100 t_{m}\right) ; b_{1}=\ln \frac{318 C_{\mathrm{v}} D_{m}^{\left(q_{\mathrm{v}}-1\right)} 100^{\left(x_{\mathrm{v}}+y_{\mathrm{v}}\right)}}{T^{m} B_{m}^{u_{\mathrm{v}}} z^{p_{\mathrm{v}}}}$; $b_{2}=\ln \frac{1,2 N_{\mathrm{sp}} \eta 100^{\left(x_{N}+y_{N}\right)}}{C_{N} 10^{-5} D_{m}^{q N} B_{m} z k_{N 1} k_{N 2}} \quad ; \quad b_{3}=\ln \frac{C_{S} D_{m}^{q S}(100)^{\left(1+x_{S}\right)} k_{S 1} k_{S 2} k_{S 3} k_{S 4}}{B_{m}^{u}} \quad ;$ $b_{4}=\ln \frac{318^{z} \theta 100^{\left(x_{\theta}+y_{\theta}\right)} \theta_{\mathrm{cr}}}{C_{\theta} D_{m}^{\left(z_{\theta}-x_{\theta}\right)} B_{m}^{u_{\theta}}} ; \quad b_{5}=\ln n_{\mathrm{sp} \min } ; \quad b_{6}=\ln n_{\mathrm{sp} \mathrm{max}} ; \quad b_{7}=\ln \frac{100 S_{\mathrm{m} . t \min }}{z} ;$ $b_{8}=\ln \frac{100 S_{\mathrm{m} \cdot t \max }}{z} ; b_{9}=\ln \left(100 t_{\text {m.min }}\right) ; b_{10}=\ln \left(100 t_{\text {m.max }}\right) ; b_{11}=\ln \frac{1000 v_{\text {al } \min }}{\pi D_{m}}$; $b_{12}=\ln \frac{1000 v_{\text {al.max }}}{\pi D_{m}} ; f_{0}=\ln f_{m} ; \quad c_{0}=\ln A=\ln \left(\frac{100 L}{z}\right)$.

The resulting system of linear constraint inequalities (22) and the linear function $\mathrm{f}_{0}$ are a mathematical model for determining rational machining conditions for the shaping of workpieces by end mills at finishing operations.

The solution of the problem can be simplified by reducing the linear system (22). To carry out mathematical transformations, it is necessary to state $x_{1}$ from the constraintinequality associated with the cutting properties of the tool, which are largely determined by its tool life:

$$
x_{1}=b_{1}-y_{v} x_{2}-x_{v} x_{3}
$$

then substitute its value in all other inequalities of system (22). When milling, the constraint which is associated with the cutting properties of the tool is one of the main constraints. As a result, we will get a new system containing two unknowns $x_{2}$ and $x_{3}$ : 


$$
\begin{aligned}
& \int\left(y_{N}-y_{v} z_{N}\right) x_{2}+\left(x_{N}-x_{v} z_{N}\right) x_{3} \leq b_{2}-z_{N} b_{1} ; \\
& x_{2}+\quad x_{s} x_{3} \leq b_{3} ; \\
& \left(y_{\theta}-y_{v} z_{\theta}\right) x_{2}+\left(x_{\theta}-x_{v} z_{\theta}\right) x_{3} \leq b_{4}-z_{\theta} b_{1} \\
& -y_{v} x_{2}-\quad x_{v} x_{3} \geq b_{5}-b_{1} \text {; } \\
& -y_{v} x_{2}-\quad x_{v} x_{3} \leq b_{6}-b_{1} ; \\
& \left(1-y_{v}\right) x_{2}-\quad x_{v} x_{3} \geq b_{7}-b_{1} \text {; } \\
& \left(1-y_{v}\right) x_{2}-\quad x_{v} x_{3} \leq b_{8}-b_{1} \text {; } \\
& x_{3} \geq b_{9} \text {; } \\
& x_{3} \leq b_{10} \text {; } \\
& -y_{v} x_{2}-\quad x_{v} x_{3} \geq b_{11}-b_{1} \\
& -y_{v} x_{2}-\quad x_{v} x_{3} \leq b_{12}-b_{1} \\
& f_{0}=\left(c_{0}-b_{1}\right)+\left(y_{v}-1\right) x_{2}+x_{v} x_{3}
\end{aligned}
$$

Since under the conditions of the specific task $c_{0}-b_{1}$ is a constant value, it means that the objective function will reach the smallest value in the case when the unknown $x_{2}$ takes maximum $\left(\left(y_{v}-1\right)\right.$ - negative value), and $x_{3}$ is the minimum admissible value satisfying the constraint system (23).

The developed mathematical model was realized in the calculation program. For example, the calculation of the cutting mode for machining of the ledge in the box-like workpiece which are made of a titanium alloy VT6 (an. 6Al-4V), with a four-tooth carbide end mill, with a diameter of $12 \mathrm{~mm}$, with a length of machined surface of $70 \mathrm{~mm}$, a milling depth of $10 \mathrm{~mm}$, a milling width of $2 \mathrm{~mm}$ and ensuring a dimensional accuracy of 10 grades (IT10) and roughness surface $-R z 20$ on the machine $6 \mathrm{~T} 82 \mathrm{G}-1$, it showed that the rotational speed of the mill should be equal to $630 \mathrm{rpm}(\mathrm{v}=23.8 \mathrm{~m} / \mathrm{min})$, and the feed per tooth is $0.04 \mathrm{~mm} /$ tooth. The machining time is 2.63 minutes.

\section{Conclusion}

Thus, a linear mathematical model is obtained that allows to determine the most advantageous machining conditions for finishing operations of end milling of workpieces, realized in the calculation program.

\section{References}

1. V.F. Bobrov. Osnovy teorii rezaniya metallov (M.: Mashinostroenie, 1975)

2. A.N. Volkov, Rezhimy rezaniya aviacionnyh materialov pri frezerovanii: Uchebnoe posobie (Samara: Samar. gos. aehrokosm. un-t, 1994)

3. B.A. Kravchenko, K.F. Mitryaev, Obrabotka i vynoslivost' vysokoprochnyh materialov (Kujbyshev: Kujbyshevsk. kn. iz-vo, 1968)

4. A.D. Loktev, I.F. Gushchin, V.A. Batuev et al., Obshchemashinostroitel'nye normativy rezhimov rezaniya: Spravochnik: V 2-h t.: T. 1 (M.: Mashinostroenie, 1991)

5. D.A. Lastochkin, D.L. Skuratov, Sovershenstvovanie metoda opredeleniya racional'nyh uslovij formoobrazovaniya poverhnostej na okonchatel'nyh operaciyah mekhanicheskoj obrabotki zagotovok, Vestnik Samar. gos. aehrokosm. unta, №2 (10), CH.1, p. 197-202 (2006) 